\title{
ESPAÇOS LIVRES PARA BRINCAR: ESTUDO DA REGIONAL GRANDE IBES, VILA VELHA-ES
}

\author{
SANGALI, Giullianna da Silva de Mello \\ Universidade Vila Velha, e-mail: gsangali99@gmail.com \\ RAMOS, Larissa Leticia Andara Ramos \\ Universidade Vila Velha, e-mail: Larissa.ramos@uvv.br \\ JESUS, Luciana Aparecida Netto de \\ Universidade Federal do Espírito Santo, e-mail: Luciana.njesus@gmail.com \\ KONDE, Karla Moreira \\ Universidade Federal do Espírito Santo, e-mail: karlamconde@hotmail.com
}

\begin{abstract}
RESUMO
Esta pesquisa tem como tema os espaços livres de uso público, com foco nos espaços para brincar e seu papel no desenvolvimento da infância, no enriquecimento sociocultural e na construção de cidades inclusivas, acolhedoras e que potencializem o ciclo completo da convivência urbana. Busca realizar uma análise crítica dos espaços livres para práticas sociais, tendo como recorte a Regional Grande Ibes, município de Vila Velha-ES, de modo a verificar e compreender de que maneira esses espaços estão incluindo as infâncias contemporâneas. $O$ trabalho foi desenvolvido em quatro etapas metodológicas: Contextualização do tema; Estudo de exemplos de projetos; Mapeamento dos espaços livres para brincar e Análises dos espaços. A análise apresentada, além de fornecer reflexões sobre a qualidade dos espaços para 0 brincar, indicam que as áreas infantis analisadas necessitam de um novo olhar voltado a atender as reais necessidade deste público.
\end{abstract}

Palavras-chave: Espaço público, Infâncias contemporâneas, Cidade Inclusiva.

\begin{abstract}
This research has as its theme the open spaces for public use, with a focus on play spaces and their role in the development of childhood, socio-cultural enrichment and the construction of inclusive, welcoming cities that enhance the complete cycle of urban coexistence. It seeks to perform a critical analysis of free spaces for social practices, taking as a cut the Regional Grande Ibes, municipality of Vila Velha-ES, in order to verify and understand how these spaces are including contemporary childhoods. The work was developed in four methodological stages: Contextualization of the theme; Study of project examples; Mapping of spaces for play and analysis of spaces. The analysis presented, besides providing reflections on the quality of play spaces, indicate that the mapped children's areas need a new look aimed at meeting the real need of this public.
\end{abstract}

Keywords: Public space, Contemporary childhood, Inclusive City.

\section{INTRODUÇÃO}

O brincar é uma prática social fundamental para o desenvolvimento da criança. É de extrema importância que o brincar seja valorizado e incentivado pois configura a fase de aprendizado e de relação com processos que acrescentam novas experiências, criatividade, racionalização, domínio de linguagem e consciência de cidadania. A brincadeira permite que a criança

SANGALI, G.; RAMOS, L.; JESUS, L.; KONDE, K. Espaços livres para Brincar: Estudo da Regional Grande Ibes - Vila Velha/ES. In: SIMPÓSIO BRASILEIRO DE QUALIDADE DO PROJETO NO AMBIENTE CONSTRUÍDO, 6., 2019, Uberlândia. Anais... Uberlândia: PPGAU/FAUeD/UFU, 2019. p. 447-457. DOI https://doi.org/10.14393/sbqp19041. 
se integre socialmente e desenvolva sentimentos de apropriação e pertencimento dentro do espaço urbano (DIAS, 2018).

A cidade é o lugar ideal para a socialização e aprendizado das crianças. É nela que as crianças desfrutam de seus direitos e deveres, compreendem que pertencem a um grupo social e que são responsáveis pelo bem comum, chamado espaço público. Diante disso, é essencial promover às crianças o direito à cidade, à vida urbana e ao lazer, por meio do brincar.

São nos espaços públicos das grandes cidades, onde as possibilidades de relações e interações sociais, de jogos e brincadeiras ao ar livre para acontecem. Conectada a sua comunidade, através das vivências, a criança desenvolve sua autoestima e autonomia como autora de transformações, tornando-se capaz de interferir positivamente no desenvolvimento e crescimento futuro da cidade.

O planejamento do espaço público infantil deve atender a condições de apropriação e as restrições dos usuários, entendendo que o público infantil é composto pela faixa etária de 0 a 12 anos e que possui necessidades diferentes, ressaltando ainda que espaços seguros, acessíveis, atrativos e diversificados influenciam no processo de apropriação e vivência urbana (COTRIM, BICHARA, 2013). Sendo assim, os projetos para espaços livres para brincar necessitam instigar a iniciativa e a curiosidade da criança, sem adiantar-se as suas formas de apropriação. Devem ainda dispor de equipamentos que garantam às crianças o desenvolvimento e a ludicidade, para que assim, seja possível resgatar os hábitos do brincar nos espaços livres, gerando vitalidade e progressão à cidade.

Em decorrência do crescimento exacerbado dos interesses do mercado capitalista e da expansão dos espaços privados, a "cultura do medo" vem fortalecendo e tornando os espaços urbanos menos frequentados. A infância livre está sendo cada vez mais sufocada pelas transformações da sociedade atual e sendo prejudicada pela ausência de oportunidades de se apropriar da cidade, esvaziando os espaços públicos e perdendo sua representatividade (BAUMAN, 2001).

Dias (2018) afirma que as cidades ainda têm um longo caminho na promoção da atenção às crianças, apresenta que os planejadores devem considerar a requalificação desses espaços integrados ao tecido urbano gerando vitalidade a cidade para que possam ser vividos pelas infâncias contemporâneas. Sendo assim, os espaços livres para brincar devem dispor de equipamentos que garantam às crianças o desenvolvimento e a ludicidade, para que assim, seja possível resgatar os hábitos do brincar nos espaços livres, gerando vitalidade e progressão à cidade.

Nesse contexto, a presente pesquisa busca refletir sobre a qualidade dos espaços para o brincar na cidade e compreender a qualidade dos espaços destinados às infâncias contemporâneas, tendo como recorte a Regional Grande Ibes, situada munícipio de Vila Velha-ES. A discussão é realizada conforme parâmetros estudados pelo grupo de pesquisa "Paisagem Urbana e Inclusão" da Universidade Vila Velha e Universidade Federal do Espírito Santo e que busca, a partir da avaliação de praças, discutir as diferenças de tratamento do espaço público na região metropolitana de Vitória. 


\section{MATERIAL E MÉTODO}

Considerada a cidade mais antiga do Estado do Espírito Santo, Vila Velha é também a segunda mais populosa do Estado. É dividida em cinco regiões administrativas e possui 414.586 habitantes em uma área de unidade territorial de 209,965 km2 (VILA VELHA, 2008; IBGE, 2010).

A Grande Ibes (ilustrada na Figura 01) é a segunda regional do municipio em densidade habitacional, com a presença de bairros planejados, de ocupação antiga. Trata-se da região administrativa de maior quantidade, por bairros, de espaços livres de uso público para práticas sociais, totalizando 20 praças. De acordo com a SEMPLA (2013), cerca de $20 \%$ da população da Regional é constituída por crianças e adolescente de 0 a 14 anos, público esse que merece atenção e sugere estudos que analisem a qualidade desses espaços.

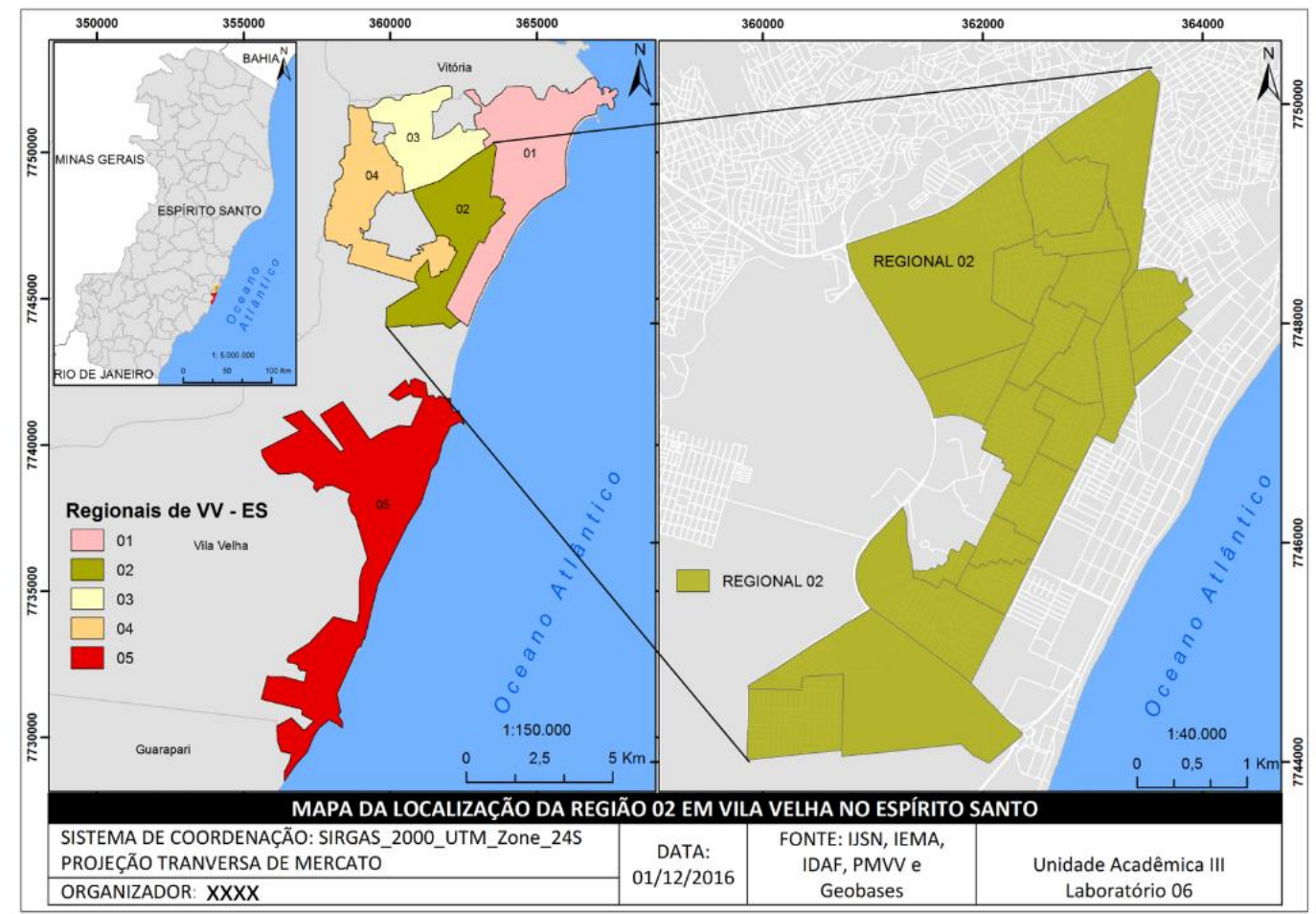

Figura 1 - Localização da regional de estudo.

Fonte: Elaborada pelas autoras no programa ArcGis (2019).

Para o desenvolvimento desse trabalho foi necessário um aprofundamento do tema, tendo como principais autores: Sartori, Alvarez e Sommerhalder (2015); Dias (2018); Cotrim e Bichara (2013) e Medeiros (2016) que buscam discorrer sobre a importância do brincar na cidade. Paralelamente a revisão bibliográfica, foram pesquisados exemplos significativos de espaços públicos destinados ao público infantil com padrões inclusivos e educativos.

O mapeamento dos espaços a serem analisados foi realizado no software ArcGIS - ferramenta de geoprocessamento e Sistema de Informação Geográfico (SIG) - a partir de dados cedidos pela Prefeitura Municipal de Vila Velha, imagens do Google Earth e visitas as praças. Cada um desses espaços foram fotografados, filmados e, por meio da técnica de observação, os dados necessários para a análise foram coletados. 
Após a leitura do referencial teórico e da compreensão dos estudos de caso, foram selecionados critérios de análises visando avaliar se os espaços mapeados estão atendendo as necessidades das infâncias contemporâneas.

Sendo assim, tendo em vista que esse artigo visa apresentar os resultados da aplicação e análise dos espaços livres de uso público destinados às infâncias contemporâneas da Regional Grande lbes, foram identificados 8 indicadores agrupados nas categorias proteção física, ambiente e estímulos - afim de garantir qualidade à vivência das crianças no espaço urbano.

Para a classificação e pontuação foi considerado o sistema de notas utilizado pelo iCam (ITDP Brasil, 2018), no qual, a partir dos respectivos parâmetros, é atribuída uma nota de 0 (zero) a 3 (três) para o indicador a ser estudado, variando de "ótimo" a "insuficiente". A Tabela 1 a seguir, descreve os parâmetros de análise atribuídos para cada indicador, assim como a pontuação correspondente, utilizados na análise das praças desta pesquisa.

Tabela 1 - Relação de indicadores e parâmetros de análise.

\begin{tabular}{|c|c|c|c|c|c|}
\hline \multirow{2}{*}{ CAT. } & \multirow{2}{*}{ INDICADORES } & \multicolumn{4}{|c|}{ PARÂMETROS DE ANÁLISE } \\
\hline & & Ótimo & Bom & Suficiente & Insuficiente \\
\hline \multirow{4}{*}{ 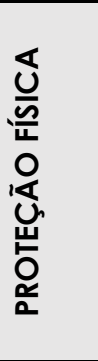 } & Localização & $\begin{array}{l}\text { central e com } \\
\text { cercamento }\end{array}$ & $\begin{array}{l}\text { central e sem } \\
\text { cercamento }\end{array}$ & $\begin{array}{l}\text { próximo as } \\
\text { vias e com } \\
\text { cercamento }\end{array}$ & $\begin{array}{l}\text { próximo as } \\
\text { vias e sem } \\
\text { cercamento }\end{array}$ \\
\hline & Material do Piso & $\begin{array}{c}\text { piso } \\
\text { emborrachado }\end{array}$ & $\begin{array}{l}\text { grama natural } \\
\text { ou sintética }\end{array}$ & Areia & $\begin{array}{l}\text { piso asfáltico/ } \\
\text { intertravado }\end{array}$ \\
\hline & $\begin{array}{c}\text { Material dos } \\
\text { brinquedos }\end{array}$ & $\begin{array}{l}\text { plástico } \\
\text { rotomoldado }\end{array}$ & $\begin{array}{c}\text { madeira ou } \\
\text { emborrachado }\end{array}$ & Concreto & metal \\
\hline & $\begin{array}{c}\text { Estado de } \\
\text { Conservação }\end{array}$ & ótimo & bom & Suficiente & insuficiente \\
\hline 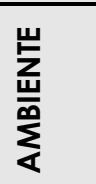 & $\begin{array}{l}\text { Área de sombra de } \\
\text { copa de árvore }\end{array}$ & $\geq 75 \%$ da área & $\geq 50 \%$ da área & $\geq 25 \%$ da área & $<25 \%$ da área \\
\hline \multirow{3}{*}{ 号 } & Estímulos Motores & $\begin{array}{c}\geq 5 \\
\text { equipamentos }\end{array}$ & $\begin{array}{c}\geq 4 \\
\text { equipamentos }\end{array}$ & $\begin{array}{c}\geq 3 \\
\text { equipamentos }\end{array}$ & $\begin{array}{c}<2 \\
\text { equipamentos }\end{array}$ \\
\hline & $\begin{array}{c}\text { Estímulos } \\
\text { Sensoriais/Lúdicos }\end{array}$ & $\geq 3$ estímulos & $\geq 2$ estímulos & $\geq 1$ estímulo & $\begin{array}{l}\text { nenhum } \\
\text { estímulo }\end{array}$ \\
\hline & $\begin{array}{c}\text { Brincadeiras de } \\
\text { Regras }\end{array}$ & presença & - & - & ausência \\
\hline
\end{tabular}

Fonte: Elaborado pelas autoras (2019).

Vale destacar que o método avaliativo desenvolvido para essa pesquisa é organizado em categorias e indicadores. As categorias apresentam os principais parâmetros de referência para a avaliação e os indicadores são responsáveis pela qualificação unitária do desempenho apresentado pelo objeto de estudo.

Em relação a categoria Proteção física, foi necessário analisar a segurança e as condições de "localização" em que esses espaços são configurados. Para preservar a segurança física das crianças, os espaços para brincar precisam ser recintados e localizados fora do perímetro da praça, evitando a proximidade com a rua. O "material do piso" deve ser acessível e seguro para atender todos os públicos, assim, o pavimento emborrachado é melhor situação para pisos de áreas infantis, devido sua capacidade de reduzir o impacto e ainda de ter uma superfície homogênea e sem trepidações. A pior 
situação seria a do piso asfáltico ou intertravado que não fornece nenhuma segurança ao impacto e ainda esquenta com facilidade.

Também foi necessário observar os equipamentos infantis presentes em cada praça, esse material deve ser especificado adequadamente, evitando riscos de acidentes entre as crianças. Foram considerados "ótimo" os equipamentos infantis em plástico rotomoldado, pois esse material garante superfície lisa, permite cores variadas e ainda admite flexibilização. O metal foi considerado o pior material pois além de ser duro, esquenta demais. Ainda na categoria proteção física, foi necessário observar o estado de conservação dos brinquedos e a estrutura em geral encontrada nesses espaços.

A categoria Ambiente analisa se os espaços para brincar estão sombreados, garantindo a qualidade na permanência das crianças e de seus respectivos responsáveis. Os parâmetros consideram que o espaço para brincar com qualificação "ótima" deve possuir área sombreada maior ou igual que $75 \%$ de sua extensão.

A última categoria avalia os Estímulos disponíveis nas áreas, essa categoria é relevante para a pesquisa pois é através desses parâmetros que é possível identificar se os espaços para brincar atendem as necessidades motoras, lúdicas e sensoriais que toda criança necessita ter. Assim, para essa categoria foram elaborados 3 indicadores, o primeiro deles avalia a quantidade de equipamentos que "estimulam os sentidos motores" das crianças, como por exemplo a presença de equipamentos e brinquedos que permitem a criança rodar, subir, descer e pular. O segundo indicador analisa os "estímulos sensoriais e lúdicos" que são relevantes para atrair a atenção das crianças e também para gerar aprendizado ao brincar, como por exemplo equipamentos interativos, que estimulam os sentidos e que possibilitam estimular a criatividade e ludicidade da criança. $\bigcirc$ terceiro indicador analisa se os espaços permitem a realização de brincadeiras de regras, como por exemplo espaços de quadras e campos ou lugares em que as crianças brinquem de bolo, triciclo, bicicleta, skate, dentre outros.

\section{ANÁLISE DOS ESPAÇOS PARA BRINCAR DA GRANDE IBES}

Conforme ilustrado na Figura 2, a região Grande Ibes possui 20 praças, distribuídas em 21 bairros, sendo 01 delas com total ausência de espaço destinados ao brincar (playground, quadra ou pista de skate). Dentre as praças que possuem espaços para brincar, $95 \%$ delas possuem playgrounds (ou seja 19 praças), 60\% delas possuem também quadras (12 praças) e apenas $5 \%$ possui pista de skate ( 1 praça). 


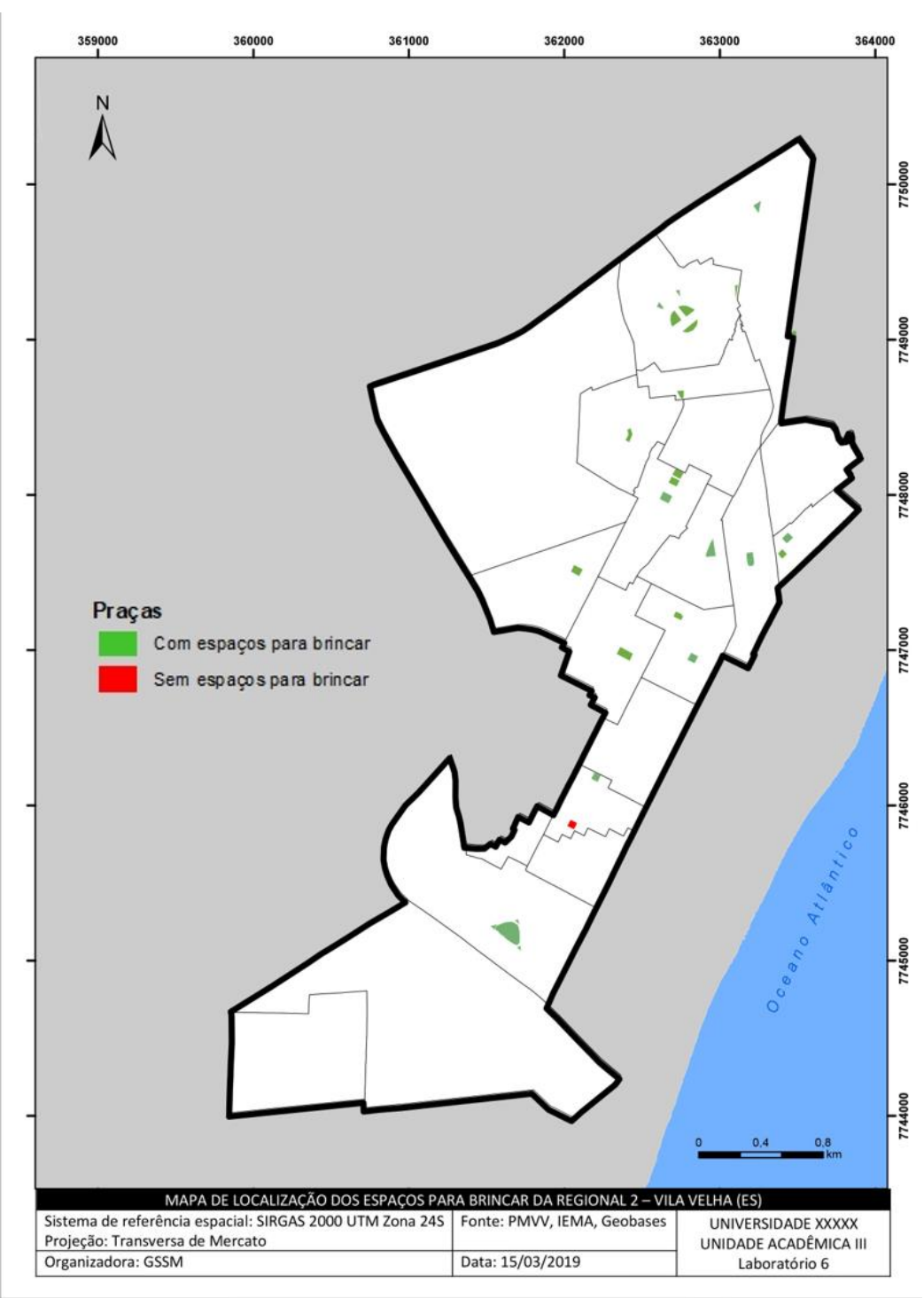

Figura 2 - Localização dos espaços para brincar.

Fonte: Elaborado pelas autoras no ArcGis (2019).

As 20 praças foram visitadas e a partir dos parâmetros estabelecidos ( ilustrada na Tabela 1 apresentada acima), as análises foram realizadas, considerando com 8 indicadores, agrupados em 3 categorias: "Proteção Física", "Ambiência" e "Estímulos".

Os resultados da análise referente a Proteção física das praças apontam (conforme observado na Figura 3) a predominância da pontuação considerada "suficiente" (evidenciada em amarelo), sendo que 15 praças alcançaram a nota 1 "suficiente" e 5 receberam a pior pontuação da análise "insuficiente" (zero). De acordo com os indicadores e parâmetros de análise estabelecidos, nenhuma praça foi considerada como "boa" ou "ótima", fato esse que assinala e evidencia a necessidade de investimentos maiores nos aspectos ligados a qualidade dos equipamentos, materiais e conservação oferecidos nesses espaços infantis. 


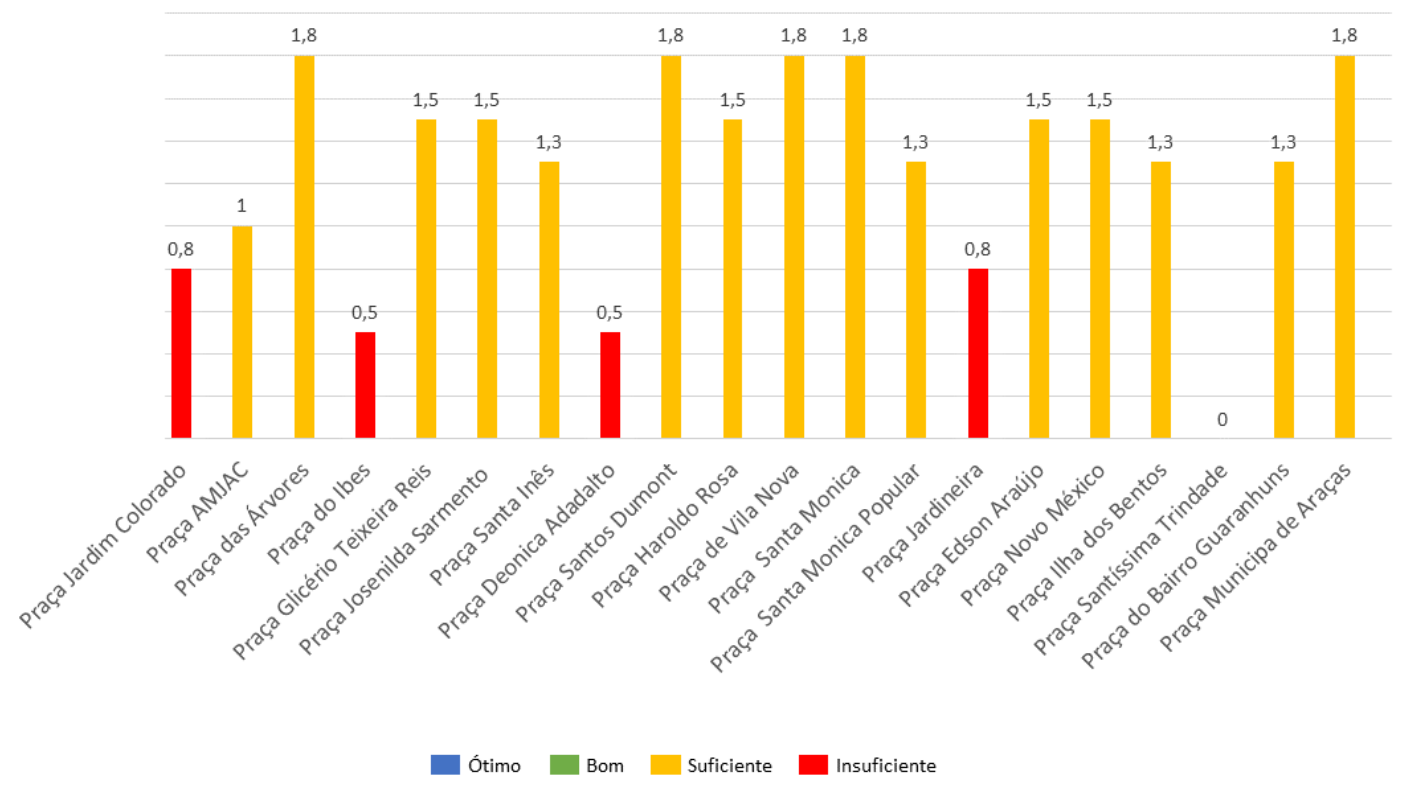

Figura 3 - Gráfico ilustrando a Pontuação da Categoria "Proteção Física". Fonte: Elaborado pelas autoras (2019).

Ainda referente a categoria Proteção física, as praças que atingiram a pior pontuação foram aquelas que de fato não cumprem com os requisitos analisados. Ao observar o indicador que mais pesou na média final e fez com que a pontuação dessas praças diminuísse foi o que avaliava a localização das áreas infantis. Em 95\% das praças os espaços para brincar estão situados ao longo do perímetro, fator esse considerado de vulnerabilidade.

Observando as notas alcançadas nas praças analisadas, referente a categoria Ambiência, percebe-se que a regional Grande Ibes apresenta um resultado melhor comparada categoria anterior. Cerca $40 \%$ das praças apresentam resultado "ótimo" (evidenciado em azul na Figura 4) em relação ao sombreamento da área infantil, qualificando e aumentando a pontuação final da regional 2. Entretanto, 4 praças obtiveram nota "insuficiente", pois possuem espaços completamente áridos, com área de sombra inferior a $25 \%$ da extensão. 
Categoria "Ambiência"

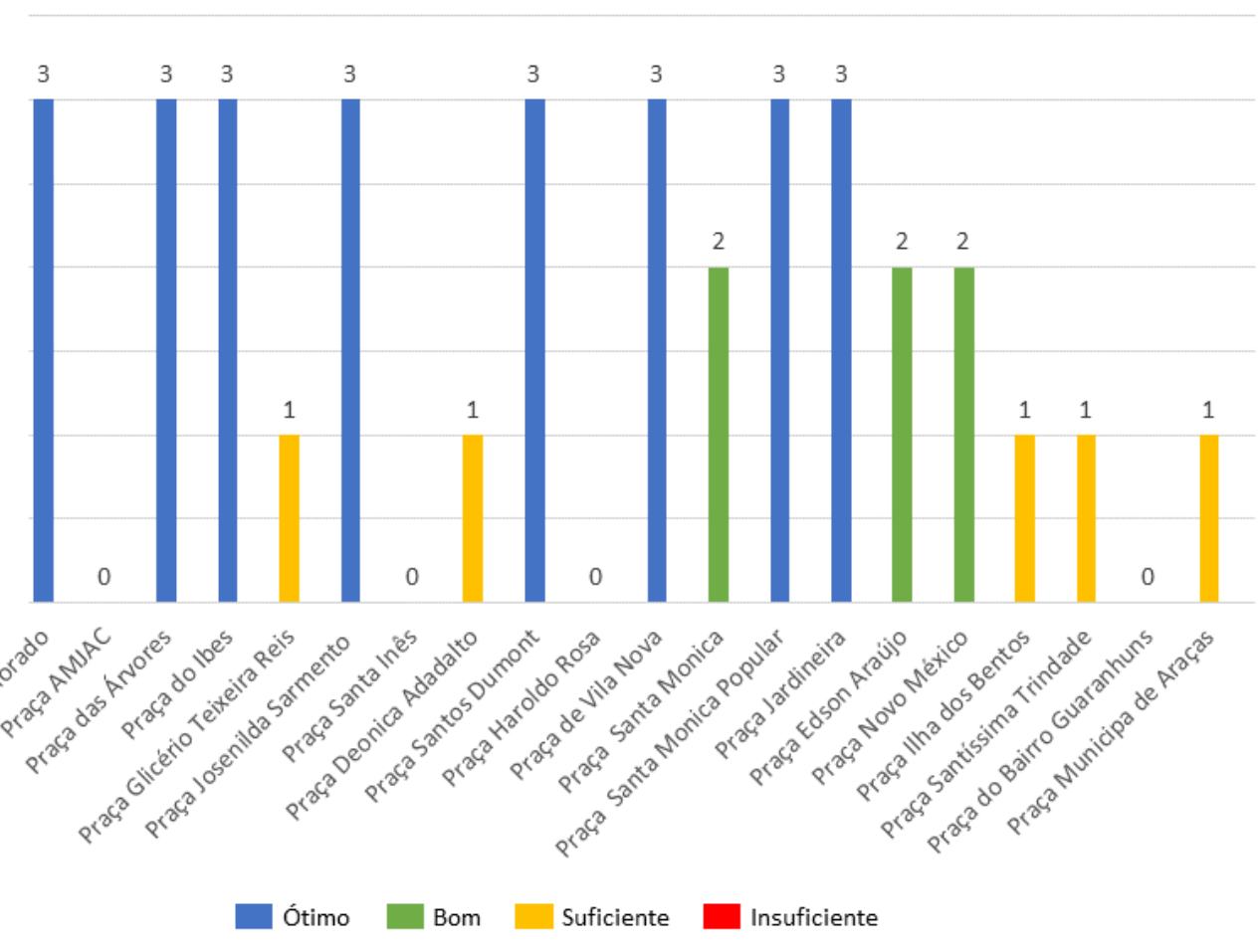

Figura 4 - Gráfico ilustrando a pontuação da Categoria "Ambiência". Fonte: Elaborado pelas autoras (2019).

As análises de sombreamento das áreas infantis resultaram que a maior parte das praças possuem suas áreas de playground parcialmente sombreadas, como mostra na Figura 5, entretanto 4 delas apresentam nenhum tipo de sombreamento, evidenciando a necessidade de intervenção.

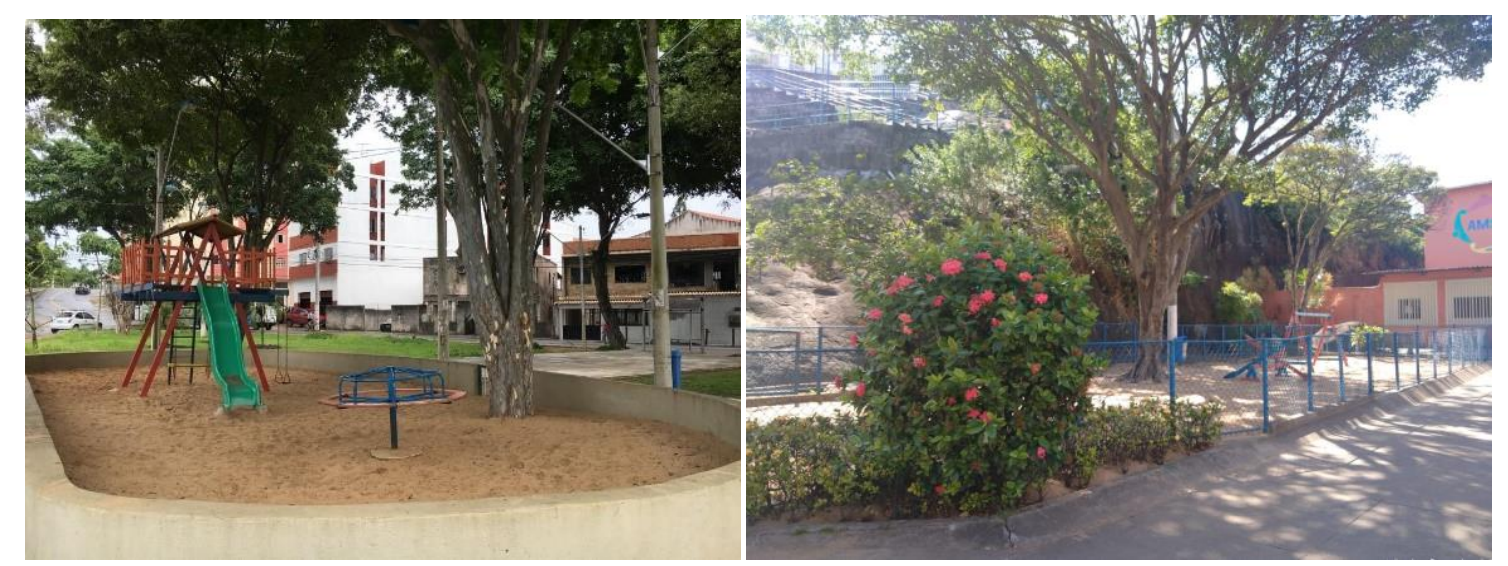

Figura 5 - Presença de áreas sombreadas.

a) Praças Santos Dumond; b) Praças das Árvores.

Fonte: Autoras (2019).

A categoria Estímulos avalia a promoção de incentivo lúdico, sensorial e motores às crianças usuárias das praças. Nas análise, tal categoria alcançou nota satisfatória já que $35 \%$ das praças alcançaram nota "boa", $40 \%$ alcançaram nota "suficiente" e 5 (ou seja $25 \%$ das praças) alcançaram a pior nota da análise (insuficiente), evidenciando que as praças necessitam de investimentos para que os equipamentos infantis disponíveis sejam mais atraentes e interativos para as crianças ( Figura 6). 


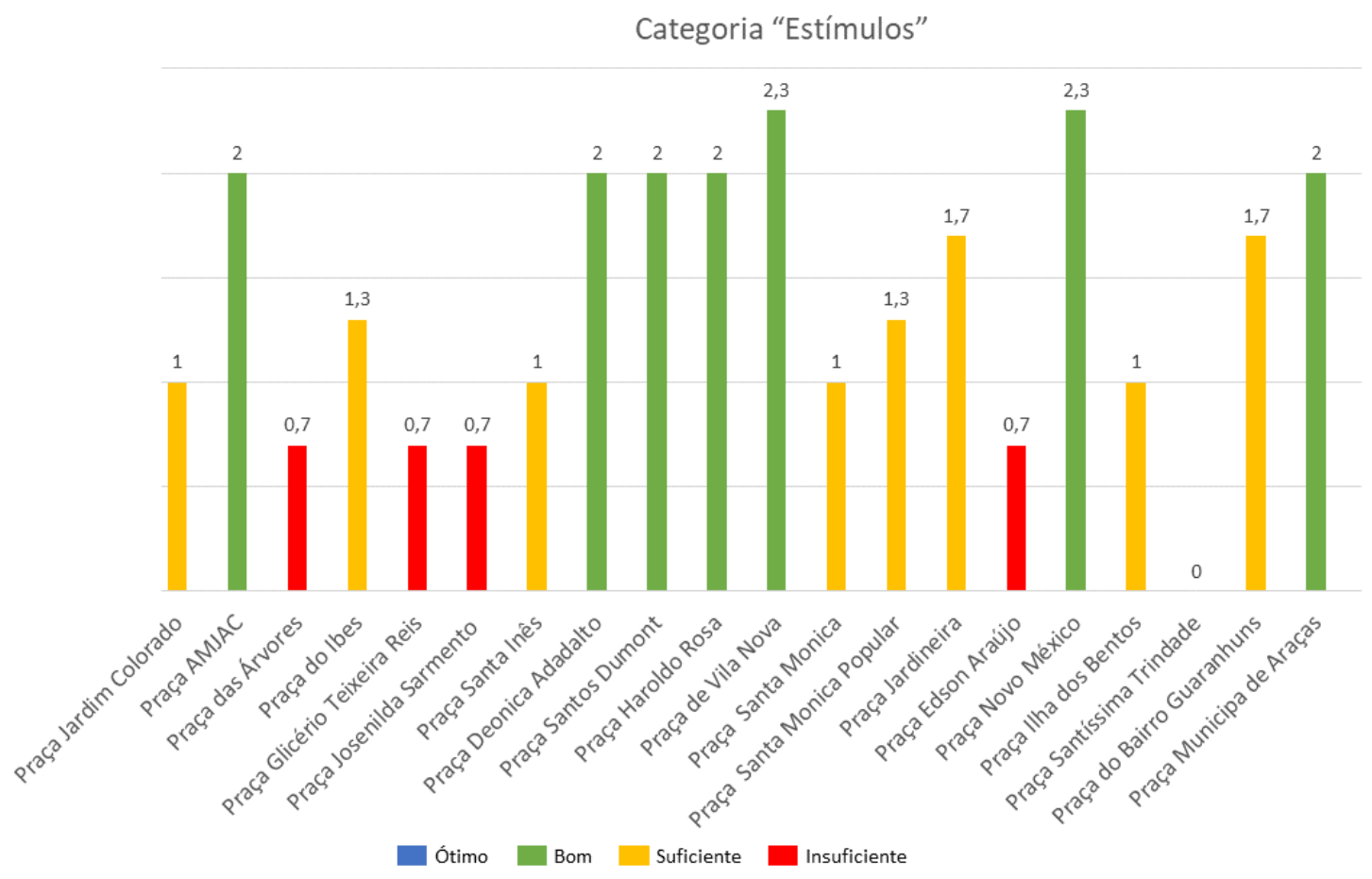

Figura 6 - Gráfico ilustrando a Pontuação da Categoria "Estímulos".

Fonte: Elaborado pelas autoras (2019).

A maioria das praças obtiveram baixa na pontuação devido ao indicador que avalia o incentivo a estímulos sensoriais/lúdicos. Apesar da maioria apresentar nota baixa, a praça de Santa Inês, ilustrada na Figura 7, obteve a nota "ótima" pois a mesma possui brinquedos que além de promoverem estímulos motores, também buscam os estímulos sensoriais e lúdicos.
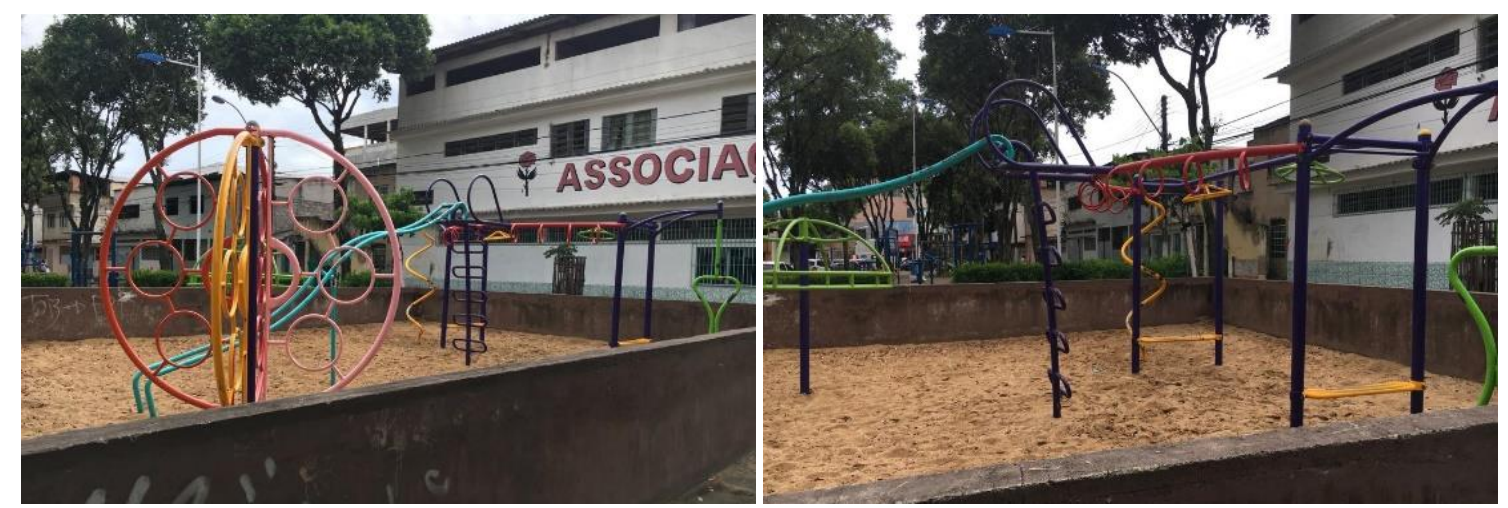

Figura 7 - área do playground da Praça Santa Inês.

Fonte: Autor (2019)

A Tabela 2 a seguir, ilustra o resultado da média por categoria das praças da Regional Grande Ibes considerada "suficiente" na análise dos espaços para brincar. A categoria "Ambiente" foi a melhor pontuada na análise, ressaltando que os espaços são arborizados e bem sombreados, qualidade essa que deve ser preservada de modo a garantir o conforto e o bem-estar das crianças nos espaços para brincar. Já a categoria "Proteção Física" recebeu a pior pontuação, ressaltando que cuidados especiais precisam ser promovidos de modo a promover a segurança das crianças no espaço público. 
Tabela 2 - Pontuação Geral da Regional 2.

\begin{tabular}{|c|c|}
\hline Categoria & Pontuação Geral \\
\hline Proteção Física & 1,3 (suficiente) \\
\hline Ambiência & 1,8 (suficiente) \\
\hline Estímulos & 1,4 (suficiente) \\
\hline Pontuação da Regional 2 & 1,5 (suficiente) \\
\hline
\end{tabular}

Fonte: Autor (2019).

\section{CONSIDERAÇÕES FINAIS}

A carência dos espaços públicos destinados as infâncias contemporâneas estão cada vez mais afastando o público infantil da cidade, não permitindo a criança a oportunidade de brincar e se desenvolver como cidadão. A cidade deve buscar entender a importância da qualidade dos espaços para brincar e unir aspectos necessários para o reconhecimento das infâncias contemporâneas.

Entretanto, conforme constatado, as áreas infantis da regional Grande lbes ainda carecem de planejamento e expansão, principalmente em relação aos aspectos ligados a proteção física e a promoção do desenvolvimento sensorial. De acordo com os indicadores e parâmetros de análise estabelecidos, nenhuma praça foi considerada como "boa" ou "ótima" em relação aos aspectos ligados a proteção física, fato esse que assinala e evidencia a necessidade de investimentos maiores em relação a qualidade dos equipamentos, materiais e conservação oferecidos nesses espaços infantis.

Em relação a categoria Estímulos, apenas $35 \%$ das praças possuem equipamentos que estimulam atividades motoras, lúdicas e sensoriais, evidenciando a pouca atratividade dos equipamentos para crianças e adolescentes. A categoria ambiente foi a mais bem avaliada, evidenciando a qualidade ambiental dos espaços para brincar no que tange ao sombreamento e a arborização

A análise apresentada fornece ainda aspectos fundamentais para elaboração de diretrizes que possam ser aplicadas nos espaços para brincar, visando também o desenvolvimento de cidades mais inclusivas.

\section{REFERÊNCIAS}

Cotrim, G. S. \& Bichara, I. D. (2013). O Brincar no Ambiente Urbano: Limites e Possibilidades em Ruas e Parquinhos de uma Metrópole. Psicologia: Reflexão e Crítica, 26(2), 388-395. Universidade Federal da Bahia, Salvador, Brasil.

SARTORI, Gabriela Dias; ALVEZ, Fernando Donizete; SOMMERHALDER, Aline. A cultura lúdica infantil em parques públicos: Qual o espaço e tempo para brincar? Educação Unisinos. 19(3):40 1-408, setembro/dezembro 2015.

DIAS, Marina Simone. Em busca dos espaços públicos de brincar: um estudo das infâncias contemporâneas na cidade de Vitória-ES. Pós, Rev. Programa Pós-Grad. Arquit. Urban. FAUUSP. São Paulo, v. 25, n. 45, p. 102-1 17, jan-abr 2018. 
MEDEIROS, Adriana Araujo et al. Acessibilidade inclusiva no parque infantil arruda câmara, p. 739-750. In: Anais do VI Encontro Nacional de Ergonomia do Ambiente Construído \& VII Seminário Brasileiro de Acessibilidade Integral [=Blucher Design Proceedings, v.2 n.7]. São Paulo: Blucher, 2016.

IBGE - Instituto Brasileiro de Geografia e estatística. Censo Demográfico, 2010. Disponível em: < https://www.ibge.gov.br/cidades-e-estados/es/vilavelha.html?>. Acesso em: 10 mar. 2019.

SEMPLA - Secretaria Municipal de Planejamento, Orçamento e Gestão. Perfil Socioeconômico por Bairros, 2013. Disponível em:

<http://www.vilavelha.es.gov.br/midia/paginas/Perfil\%20socio\%20economico\% 20R2.pdf> Acesso em: 17 mar. 2019.

BAUMAN, Zygmunt. Confiança e medo na cidade. Rio de Janeiro: Jorge Zahar Ed., 2009. 